\title{
Assessment of aortic valve tract dynamics using automatic tracking of 3D transesophageal echocardiographic images
}

Sandro Queirós $\mathrm{s}^{\mathrm{a}, \mathrm{b}, \mathrm{c}, \mathrm{d}, *}$, Pedro Morais ${ }^{\mathrm{a}, \mathrm{b}, \mathrm{c}, \mathrm{e}}$, Wolfgang Fehske ${ }^{\mathrm{f}}$, Alexandros Papachristidis ${ }^{\mathrm{g}}$, Jens-Uwe Voigt ${ }^{\mathrm{h}}$, Jaime C. Fonseca ${ }^{\mathrm{d}}$, Jan D’hooge ${ }^{\mathrm{c}, \S}$, and João L. Vilaça ${ }^{\mathrm{a}, \mathrm{b}, \mathrm{i}, \S}$

${ }^{a}$ Life and Health Sciences Research Institute (ICVS), School of Medicine, University of Minho, 4710-

057, Braga, Portugal

b ICVS/3B's - PT Government Associate Laboratory, Braga/Guimarães, Portugal

${ }^{c}$ Lab on Cardiovascular Imaging and Dynamics, KU Leuven, Leuven, Belgium

${ }^{\mathrm{d}}$ Algoritmi Center, School of Engineering, University of Minho, Guimarães, Portugal

e Instituto de Ciência e Inovação em Engenharia Mecânica e Engenharia Industrial, Faculdade de

Engenharia, Universidade do Porto, Porto, Portugal

${ }^{\mathrm{f}}$ Department of Cardiology, St Vinzenz-Hospital, Cologne, Germany

g King's College Hospital NHS Foundation Trust, London, UK

${ }^{\mathrm{h}}$ Department of Cardiology, University Hospital Leuven, Leuven, Belgium

i $2 \mathrm{Ai}$ - Polytechnic Institute of Cávado and Ave, Barcelos, Portugal

$\S$ Joint last authorship

Short title: Automatic assessment of aortic valve tract dynamics in 3D-TEE

*Corresponding author:

Sandro Queirós

E-mail address: sandroqueiros@ med.uminho.pt

ORCID: 0000-0001-5259-1891

Address: Life and Health Sciences Research Institute (ICVS)

Universidade do Minho

Campus de Gualtar

4710-057 Braga

Portugal

Tel.: +351253604891

Conflict of interest: The authors declare no conflict of interest.

Acknowledgements: This work was funded by projects "NORTE-01-0145-FEDER-000013" and "NORTE-01-0145-

FEDER-024300", supported by Northern Portugal Regional Operational Programme (Norte2020), under the Portugal

2020 Partnership Agreement, through the European Regional Development Fund (FEDER). This work has also been funded by FEDER funds, through Competitiveness Factors Operational Programme (COMPETE), and by national funds, through the FCT - Fundação para a Ciência e Tecnologia, under the scope of the project POCI-01-0145FEDER-007038. The authors also acknowledge support from FCT and the European Social Found, through Programa Operacional Capital Humano (POCH), in the scope of the PhD grants SFRH/BD/93443/2013 (S. Queirós) and SFRH/BD/95438/2013 (P. Morais). The authors would also like to thank Judith Simons (St. Vinzenz-Hospital, Cologne, Germany) and Mahvish T. Elahi (KU Leuven, Leuven, Belgium) for their technical assistance in collecting all patient/image data. 


\section{Abstract}

2 Purpose: The assessment of aortic valve (AV) morphology is paramount for planning transcatheter AV 3 implantation (TAVI). Nowadays, pre-TAVI sizing is routinely performed at one cardiac phase only, usually

4 at mid-systole. Nonetheless, the AV is a dynamic structure that undergoes changes in size and shape

5 throughout the cardiac cycle, which may be relevant for prosthesis selection. Thus, the aim of this study

6 was to present and evaluate a novel software tool enabling the automatic sizing of the AV dynamically in

7 three-dimensional (3D) transesophageal echocardiography (TEE) images.

8 Methods: Forty-two patients who underwent preoperative 3D-TEE images were retrospectively analyzed

9 using the software. Dynamic measurements were automatically extracted at four levels, including the aortic

10 annulus. These measures were used to assess the software's ability to accurately and reproducibly quantify

11 the conformational changes of the aortic root and were validated against automated sizing measurements

12 independently extracted at distinct time points.

13 Results: The software extracted physiological dynamic measurements in less than 2 min, that were shown

14 to be accurate (error $2.2 \pm 26.3 \mathrm{~mm}^{2}$ and $0.0 \pm 2.53 \mathrm{~mm}$ for annular area and perimeter, respectively) and

15 highly reproducible $\left(0.85 \pm 6.18\right.$ and $0.65 \pm 7.90 \mathrm{~mm}^{2}$ of intra- and interobserver variability, respectively,

16 in annular area). Using the maximum or minimum measured values rather than mid-systolic ones for device

17 sizing resulted in a potential change of recommended size in $7 \%$ and $60 \%$ of the cases, respectively.

18 Conclusion: The presented software tool allows a fast, automatic and reproducible dynamic assessment of 19 the AV morphology from 3D-TEE images, with the extracted measures influencing the device selection 20 depending on the cardiac moment used to perform its sizing. This novel tool may thus ease and potentially 21 increase the observer's confidence during prosthesis' size selection at the preoperative TAVI planning.

23 Keywords: Aortic valve sizing; 3D transesophageal echocardiography; transcatheter aortic valve 24 implantation; dynamic morphology assessment; tracking software tool. 


\section{Introduction}

Aortic stenosis (AS) is the most common heart valve disease leading to intervention in developed countries, with a prevalence of $3 \%$ in the elderly [1]. It carries a dismal prognosis without proper treatment $[2,3]$. Although surgical aortic valve replacement (SAVR) is still the standard treatment for patients with symptomatic, severe AS, transcatheter aortic valve implantation (TAVI) has quickly become a successful alternative in high-risk/inoperable patients $[1,4]$, with recent studies suggesting its use as an alternative in intermediate risk patients also [5].

Throughout the preoperative TAVI planning, imaging is vital to validate the diagnosis, grade AS severity, review the aortic valve (AV) morphology and, most importantly, select the appropriate prosthesis size based on several anatomical measurements [6-8]. Despite the lack of consensus regarding the most suitable phase of the cardiac cycle to extract these measurements (i.e. depends on local expertise), it is now generally accepted that the aortic root does undergo dynamic changes throughout the cardiac cycle $[9,10]$.

Indeed, previous studies have shown that systolic measures tend to be larger than diastolic ones, although the magnitude of conformational changes is variable between patients (e.g., depending on the severity of calcification) and across studies $[9,10]$. For these reasons, the cardiac phase chosen to perform such analysis may affect the prosthesis sizing [11-13], with some cardiologists advocating the analysis at multiple time points to best predict the optimal size $[10,14]$. With this in mind, automated methodologies have been presented to extract the AV morphology at several cardiac phases [15-17]. Despite these technological advances, automatic dynamic morphology assessment is still underexplored and underused in clinical practice, with most solutions reporting the measurements at one (or two) frames only.

Recently, a tracking algorithm based on the anatomical affine optical flow (AAOF) algorithm was proposed for left ventricle tracking in both 3D echocardiography and cardiac magnetic resonance data [1820]. Hereto, the application of the AAOF algorithm for dynamic AV morphology assessment is addressed, being the algorithm embedded in our recently presented software tool for automatic AV tract segmentation and sizing [21]. Overall, in this study, we sought to present this novel software tool for fast and automatic AV tract tracking by 3D-TEE, while investigating its applicability, robustness and reproducibility for 
1 dynamic measurements extraction for the planning of TAVI.

\section{Material and methods}

\section{Study population}

In this study, patients with symptomatic, severe AS who underwent TAVI at the St. VinzenzHospital (Cologne, Germany) from August 2014 to September 2017 were retrospectively reviewed to identify those who underwent pre-procedural 3D-TEE. Because this study intends to evaluate the dynamic behavior of the aortic root, only 3D-TEE acquisitions with a minimum frame rate of $15 \mathrm{~Hz}$ were considered. Among the 115 patients evaluated, 50 fulfilled the above criteria and were thus further assessed. Of these, and upon visual inspection by an experienced observer, eight were excluded because of strong stitching artifacts and/or poor image quality. As a result, 42 patients were enrolled in this study. Table 1 presents the clinical and echocardiographic characteristics of the study population.

\section{Image acquisition}

All patients underwent preprocedural TEE using a GE Vivid E9 or E95 (GE VingMed, Horten, Norway) ultrasound system equipped with a 6VT-D transducer. Besides two-dimensional standard imaging, the echocardiographic study included at least one electrocardiographically triggered multiple-beat 3D image acquired from a mid-esophageal position using 3D zoom mode, covering the left ventricular outflow tract (LVOT), aortic valve and aortic root (1 and 41 cases with a 4-beat and 6-beat acquisition, respectively). In cases with more than one 3D data set available, the one with the best overall image quality (on the basis of the presence/extent of acoustic shadowing or stitching artifacts) was selected for subsequent processing. These volume sequences were captured with an average frame rate of $\sim 41 \mathrm{~Hz}$ and presented an image resolution and size ranging from 0.32 to $0.59 \mathrm{~mm}$ and $162 \times 162 \times 163$ to $261 \times 261 \times 202$ voxels, respectively. Data sets were digitally stored in a raw-data format and exported to a workstation equipped with the EchoPac software (GE Healthcare). To enable offline processing with the proposed software tool, the images were then anonymized, exported into an externally-readable format, and converted to isotropic voxel spacing. 


\section{Image analysis}

The analyses were performed using custom, noncommercial, MATLAB-based (MathWorks,

3 Natick, MA) software, Speqle3D [22], in which both our previously presented AV segmentation and sizing

4 tool [21] and the novel AV tracking methodology were embedded. In brief, upon selecting the mid-systolic

5 (MS) frame, the automated analysis is divided in two independent stages: (1) the AV tract is automatically

6 delineated and the measurements at four relevant short-axis (SAx) planes (LVOT, aortic annulus, sinuses

7 of Valsalva, and sinotubular junction) are extracted for the MS frame, while enabling the user to correct the

8 delineation if required; (2) the tracking algorithm is applied to estimate the motion and deformation of the

9 AV tract throughout the entire cardiac cycle in order to propagate the segmented AV tract surface and the

10 identified SAx planes in the volumetric sequence, thereby extracting dynamic measurements at the

11 aforementioned levels. Note that, in contrast to the segmentation stage, the user is not able to interact with

12 the result of the tracking algorithm. Fig. 1 illustrates the proposed analysis pipeline. For more details about

13 the interactive analysis with the AV tract segmentation and sizing tool, the reader is kindly referred to

14 Queirós et al. [21].

15 For each enrolled patient, an observer (henceforth referred as Obs1) performed the analysis with 16 the proposed software tools. Upon running both segmentation and tracking modules, the software provides 17 the dynamic AV measurements (area, perimeter, eccentricity index, etc.) at each level in the AV tract.

\section{Intra- and interobserver reproducibility}

To establish the interobserver reproducibility of the extracted dynamic measurements, a second

observer reanalyzed each dataset (henceforth referred as Obs2). Moreover, the first observer repeated the

21 analysis after 15 days (henceforth referred as Obs1R), allowing to also assess the intraobserver 22 reproducibility. Each observer was blinded to the results of the other.

\section{Independent segmentation-based measurements}

To assess the tracking accuracy, for each case, the first observer repeated the Speqle3D interactive 
1 for the aortic annulus (AoA) in each frame. For the sake of representativeness, the chosen frames were

2 equally distributed along the cycle. For the sake of simplicity, these analyses will be referred to as

3 segmentation-based ones throughout the rest of the document.

\section{Theoretical prosthesis size selection}

The clinical significance of the AV tract dynamics was evaluated by assessing the influence of the dynamic measurements on prosthesis sizing. In this sense, for each patient, manufacturer-recommended sizing algorithms $[23,24]$ were applied to the AoA area measurements extracted at different cardiac time points, identifying the theoretical prosthesis size for each. Because the sizing charts present an overlap between prostheses' sizes, five sizing groups were considered, namely 23, 23/26, 26, 26/29 and 29-mm.

Because these recommendations were originally created on the basis of multidetector row computed

11 tomographic area measures, all measures were corrected to remove the systematic difference between

12 modalities, as previously described in Queirós et al. [21].

\section{Evaluation approach and statistical analysis} variables as frequencies. The median and interquartile range (IQR) is reported for unequally distributed continuous variables (tested by the D’Agostino-Pearson omnibus normality test). Two-tailed paired $t$-tests were used to test for significant differences between equally distributed continuous variables. To assess agreement between tracking- and segmentation-based measures, Bland-Altman (BA) analyses [25] were performed, computing both biases and limits of agreement (LOA). BA analyses were also used to quantify the intra- and interobserver variability for the dynamically extracted measures, calculating the agreement between repeated measures. The statistical significance of the biases was tested using a two-tailed onesample $t$-test against zero, while a two-tailed $F$-test was used to compare the LOA. All tests assumed significance for a $p$-value $<0.05$. The statistical analyses were performed using SPSS Statistics version 20 (IBM, Armonk, NY) and GraphPad Prism version 6.01 (GraphPad Software Inc., CA, USA). 
extraction of dynamic measurements) was recorded.

To assess the potential effect of the dynamic measurements taken, the sizing agreement between the theoretically selected prosthesis size for the mid-systolic frame (often used for these measurements) and other time points was evaluated. Maximum and minimum measurements, as well as measures at specific cardiac moments (namely mid-systole, end-systole and end-diastole), were also considered. Moreover, the agreement against the truly implanted size was also evaluated. In all scenarios, borderline cases (i.e. whose measures lay in the overlapping regions in the sizing guide) were considered successfully sized if either of the possible sizes matches the other approach's size (or sizes, if also in the overlapping region).

\section{Results}

\section{Dynamic aortic valve morphology assessment}

Fig. 2 illustrates some tracking results, together with the extracted dynamic area and perimeter values for the four studied levels (some example videos are also provided in Online Resource 1 to 5). For each measurement (Obs1 analyses), the maximum and minimum area and perimeter during the cardiac cycle were identified. Table 2 shows the average values (and ranges) for each, as well as the absolute and relative differences. Both area and perimeter measures varied significantly throughout the cycle at the four levels, with the perimeter showing smaller relative changes than the area $(P<0.0001$, in a paired $t$-test). Among the studied levels, the LVOT presented larger relative changes, followed by the AoA, with both the sinuses of Valsalva (SoV) and the sinotubular junction (STJ) presenting smaller changes over time.

\section{Accuracy test against independent segmentation-based measurements}

The performance of the proposed tracking algorithm was validated by computing the agreement between the dynamically extracted measures for the AoA plane and the segmentation-based ones, for the four frames independently analyzed by the first observer (in a total of 168 area/perimeter values). Overall, the tracking-derived measures had an agreement of $2.2 \pm 26.3 \mathrm{~mm}^{2}$ and $0.0 \pm 2.53 \mathrm{~mm}$ for AoA area and perimeter values, respectively (see examples in Fig. 3). No significant biases were found, while the LOA were similar to the ones reported among observers for an interactive analysis with the previously proposed 
AV tract segmentation framework (SD of $22.7 \mathrm{~mm}^{2}$ and $2.2 \mathrm{~mm}$ for area and perimeter, respectively) [21].

\section{Reproducibility experiment}

To evaluate the reproducibility of the extracted measures, the AoA dynamic measurements obtained in each of the three analyses (Obs1, Obs2 and Obs1R) were gathered. Fig. 3 presents some example measurement curves. For each pair of analyses (Obs1 vs. Obs1R and Obs1 vs. Obs2, intra- and interobserver, respectively), the difference between measured values was calculated, and the average and SD computed over all time points and datasets. To remove the bias introduced by the different MS values measured in each of the observers' analyses (see bias at MS in Fig. 3), this value was subtracted to the entire curve before computing the agreement. This allows to assess the true difference in terms of measures' variation along the cycle when the tracking is initialized with different surfaces and SAx planes. Indeed, even if the observer chooses to segment the AV tract closer or farther from the wall (which depends on personal preferences and/or on the segmentation algorithm), one expects the measured value to vary similarly across the cycle.

Table 3 presents the intra- and interobserver agreement for area and perimeter measures obtained at all anatomical levels. Interestingly, both intra- and interobserver reproducibility presented significantly narrower LOA when compared to the variability in measurements extracted via independent segmentationbased analyses [21]. Fig. 4 presents the boxplots for intra- and interobserver agreements over time. Overall, there is a tendency for higher reproducibility (lower IQR) at the frames closer to the reference one (i.e. MS), progressively decreasing (higher IQR) in frames farther from it (i.e. larger number of propagation steps).

\section{Analysis time}

An automated dynamic analysis took, on average, $77.4 \pm 12.1 \mathrm{sec}$. The reported time includes the frame selection and interactive segmentation step (around $1 \mathrm{~min}$, as previously reported in Queirós et al. [21]), plus the tracking step (less than $15 \mathrm{sec}$, half of which used in the motion estimation stage over the whole sequence and half used for the surface/planes propagation stage).

\section{Influence on prosthesis size}

The distribution of the theoretically selected prostheses sizes for the distinct time points evaluated, 
1 plus the clinically implanted valve, is illustrated in Fig. 5, together with the sizing agreement of each

2 moment against predicted mid-systolic and true implanted sizes. Overall, the higher sizing agreements

3 against predicted mid-systolic sizes were found for measures extracted during the systolic phase (100\%

4 agreement), with lower agreements being obtained during diastole (95\% to 98\%). When compared against

5 the implanted sizes, the highest agreement was found for the early systolic phases (i.e. maximum measured

6 value, and between $10 \%$ and $30 \%$ of the R-R interval; with $86 \%$ agreement), being once again lower for

7 diastolic time points (between $69 \%$ and $74 \%$ ).

\section{Discussion}

In this study, we present and evaluate a novel software tool for dynamic assessment of the AV tract morphology in 3D transesophageal echocardiographic images. After automatic segmentation and sizing of

11 the AV tract in a mid-systolic frame with a previously presented tool [21], this novel software is able to

12 automatically track the AV tract throughout the TEE volume sequence, thus extracting dynamic

13 measurements at distinct anatomical levels. The accuracy of the measurement curves was assessed against

14 independent segmentation-based analyses at different time points, while their robustness was studied by

15 comparing two analyses done by the same or different observers. In both scenarios, the software proved to

16 be feasible, extracting accurate and reproducible dynamic measurements, which may be an added value for

17 preoperative valve sizing.

The proposed software tool showed to be able to accurately track the aortic wall movement (see example videos), being able to locally capture its heterogeneous deformation. Indeed, one expects the LVOT wall to present larger motion throughout the cycle (see Fig. 2C) as a result of the interaction with the mitral

21 valve opening and closing [28]. Moreover, the aortic annulus is also known to present conformational changes throughout the cycle (and not only size-related changes), whereas other regions (such as the sinuses) may present lower deformation or only increase in size because of the passage of blood through the valve

24 (see Appendix A). Overall, the software's feasibility and accuracy were demonstrated by the physiological 
reports $[9,10,12-14,29-33]$. Moreover, the fact that the maximum/minimum measured value varied in terms of cardiac moment across the study population (Appendix A, Fig. 7) also demonstrates the software's relevance for clinical practice, as these measures can be extracted throughout the entire cycle, rather than in a single time point, and thus allow to more accurately size the prosthesis.

(

In addition, the proposed software showed accurate and reproducible results across all experiments (Fig. 3, Fig. 4 and Table 3). When compared to independent segmentation-based analyses performed at multiple frames along the cardiac cycle, an excellent agreement was obtained, with LOA similar to the ones reported between observers using the previously proposed segmentation framework [21]. Remarkably, in terms of tracking reproducibility, even narrower limits of agreement were found (Table 3), either between analyses done by the same observer or by two distinct observers. When comparing the four studied levels, the STJ level presented LOA similar to the AoA plane, whereas both LVOT and SoV showed slightly wider LOA. This result is, to a large part, related to the variability in automatically positioning the SAx planes themselves. Indeed, while both AoA and STJ levels are related to fixed anatomical positions (i.e. passing through the leaflets' nadirs and the transition between sinuses and ascending aorta, respectively), the LVOT and SoV are positioned with respect to other anatomical cues (i.e. the LVOT level is below the AoA plane, whereas the SoV should pass at the sinuses' bulges) and their exact placement is thus less reproducible. Note also that, for any tracking algorithm, the LVOT's faster motion is the most critical region, and may thus present sub-optimal results, especially if the acquisition frame rate is low or the image quality unsatisfactory. This can also help explain the slightly lower reproducibility at this level. Between the AoA and STJ, the former had narrower LOA, which is also related with the ease in placing the SAx plane at this level (i.e. the STJ is usually close to the limits of the image's field-of-view, which hampers its assessment). Nevertheless, all LOA were below the interobserver variability found for independent segmentation-based analyses. Given that the segmentation and sizing software tool has already shown increased interobserver reproducibility compared to manual delineation [21], this result reinforces the advantage of a tracking-based strategy to dynamically assess the AV morphology during preoperative TAVI planning.

$$
\text { In terms of prosthesis theoretical sizing, an excellent agreement against MS-based sizing was }
$$


1 observed for all measures taken at systolic phases (Fig. 5), slightly decreasing for diastolic ones. It is

2 important to notice that, despite small enough to avoid changing the prosthesis size (hence the perfect

3 agreement), early systolic measures tended to be slightly larger than MS ones, leading to the sizing of larger

4 valves (from a specific size to the upper borderline region, or similar transitions). This occurred in 7 to $14 \%$

5 of the cases when comparing early-systolic measures (e.g., maximum measured value or $20 \%$ of the R-R

6 interval) against mid-systolic ones, and up to $60 \%$ of the cases when comparing diastolic and MS measures.

7 Moreover, when compared against true implanted sizes, early systolic measures showed a slightly better

8 agreement compared to the original cardiac moment used for sizing (the MS phase chosen by the observer

9 to perform the delineation). Altogether, these results suggest that measures taken at an early systolic phase,

10 or instead determined by identifying the maximum value in a dynamic analysis (as enabled by the proposed

11 software tool), might improve prosthesis sizing. Although it would be relevant to assess whether selecting

12 a larger prosthesis would lead to a better patient outcome, this was out of the current manuscript's scope,

13 being required a prospective study to ascertain this hypothesis.

Interestingly, the proposed software showed also to be time efficient, requiring $\sim 80 \mathrm{sec}$ only to extract the dynamic measurements for the four studied levels in a TEE volume sequence. If one would manually and independently assess the AV tract dimensions at all frames, the required analysis time would

17 be proportional to the number of analyzed frames ( 1 min per frame if using our previous segmentation and sizing software tool or around $5 \mathrm{~min}$ for a routine manual measuring analysis [26,27]). In fact, even if one would assess a few cardiac instances only (e.g., mid-systole, end-systole, diastasis and end-diastole), the analysis time would be impractical for daily routine use.

\section{Study limitations}

First, this is a single-center retrospective study, and a larger prospective study is required to validate 
1 be evaluated against tracings. However, note that the latter is the routine method used in practice. Third, the

2 software tool was validated in images acquired with an ultrasound system from a single vendor, and thus

3 the software's feasibility to images acquired in machines from other vendors must still be studied.

\section{Conclusion}

In summary, this study presents a novel fast and automatic software tool for AV tract tracking in

6 3D-TEE images, allowing the extraction of dynamic measurements. The proposed software presented

7 physiological results, while demonstrating to be accurate and reproducible with respect to independent

8 segmentation-based analyses. Moreover, it showed to be suitable for a fast, dynamic analysis, which may

9 be relevant for its use in prosthesis sizing during preoperative TAVI planning. 


\section{References}

1. Osnabrugge RL, Mylotte D, Head SJ, Van Mieghem NM, Nkomo VT, LeReun CM, Bogers AJ, Piazza N, Kappetein AP (2013) Aortic stenosis in the elderly: disease prevalence and number of candidates for transcatheter aortic valve replacement: a meta-analysis and modeling study. J Am Coll Cardiol 62 (11):1002-1012

2. Leon MB, Smith CR, Mack M, Miller DC, Moses JW, Svensson LG, Tuzcu EM, Webb JG, Fontana GP, Makkar RR (2010) Transcatheter aortic-valve implantation for aortic stenosis in patients who cannot undergo surgery. N Engl J Med 363 (17):1597-1607

3. Nishimura RA, Otto CM, Bonow RO, Carabello BA, Erwin JP, Guyton RA, O'Gara PT, Ruiz CE, Skubas NJ, Sorajja P (2014) 2014 AHA/ACC guideline for the management of patients with valvular heart disease. Circulation 129 (23):521-643

4. Vahanian A, Alfieri O, Andreotti F, Antunes MJ, Barón-Esquivias G, Baumgartner H, Borger MA, Carrel TP, De Bonis M, Evangelista A (2012) Guidelines on the management of valvular heart disease (version 2012). Eur Heart J 33 (19):2451-2496

5. Leon MB, Smith CR, Mack MJ, Makkar RR, Svensson LG, Kodali SK, Thourani VH, Tuzcu EM, Miller DC, Herrmann HC (2016) Transcatheter or surgical aortic-valve replacement in intermediate-risk patients. N Engl J Med 374 (17):1609-1620

6. Min JK, Berman DS, Leipsic J (2013) Multimodality imaging for transcatheter aortic valve replacement. Springer Science \& Business Media,

7. Zamorano J, Gonçalves A, Lancellotti P, Andersen KA, González-Gómez A, Monaghan M, Brochet E, Wunderlich N, Gafoor S, Gillam LD (2016) The use of imaging in new transcatheter interventions: an EACVI review paper. Europen Heart Journal - Cardiovascular Imaging 17 (8):835-835af

8. Bloomfield GS, Gillam LD, Hahn RT, Kapadia S, Leipsic J, Lerakis S, Tuzcu M, Douglas PS (2012) A practical guide to multimodality imaging of transcatheter aortic valve replacement. JACC Cardiovasc Imaging 5 (4):441-455

9. Hamdan A, Guetta V, Konen E, Goitein O, Segev A, Raanani E, Spiegelstein D, Hay I, Di Segni E, Eldar M (2012) Deformation dynamics and mechanical properties of the aortic annulus by 4-dimensional computed tomography: insights into the functional anatomy of the aortic valve complex and implications for transcatheter aortic valve therapy. J Am Coll Cardiol 59 (2):119-127

10. Suchá D, Tuncay V, Prakken NH, Leiner T, van Ooijen PM, Oudkerk M, Budde RP (2015) Does the aortic annulus undergo conformational change throughout the cardiac cycle? A systematic review. European Heart Journal - Cardiovascular Imaging 16 (12):1307-1317

11. Murphy DT, Blanke P, Alaamri S, Naoum C, Rubinshtein R, Pache G, Precious B, Berger A, Raju R, Dvir D (2016) Dynamism of the aortic annulus: Effect of diastolic versus systolic CT annular measurements on device selection in transcatheter aortic valve replacement (TAVR). J Cardiovasc Comput Tomogr 10 (1):37-43

12. Blanke P, Russe M, Leipsic J, Reinöhl J, Ebersberger U, Suranyi P, Siepe M, Pache G, Langer M, Schoepf UJ (2012) Conformational pulsatile changes of the aortic annulus: impact on prosthesis sizing by computed tomography for transcatheter aortic valve replacement. JACC Cardiovasc Interv 5 (9):984-994

13. von Aspern K, Foldyna B, Etz C, Hoyer A, Girrbach F, Holzhey D, Lücke C, Grothoff M, Linke A, Mohr F (2015) Effective diameter of the aortic annulus prior to transcatheter aortic valve implantation: influence of area-based versus perimeter-based calculation. The International Journal of Cardiovascular Imaging 31 (1):163-169 
14. Mehrotra P, Flynn AW, Jansen K, Tan TC, Mak G, Julien HM, Zeng X, Picard MH, Passeri JJ, Hung J (2015) Differential left ventricular outflow tract remodeling and dynamics in aortic stenosis. J Am Soc Echocardiogr 28 (11):1259-1266

15. Bersvendsen J, Beitnes JO, Urheim S, Aakhus S, Samset E (2014) Automatic measurement of aortic annulus diameter in 3-dimensional Transoesophageal echocardiography. BMC Med Imaging 14 (1):31

16. Ionasec RI, Voigt I, Georgescu B, Wang Y, Houle H, Vega-Higuera F, Navab N, Comaniciu D (2010) Patient-specific modeling and quantification of the aortic and mitral valves from 4-D cardiac CT and TEE. IEEE Trans Med Imaging 29 (9):1636-1651

17. Veronesi F, Corsi C, Mor-Avi V, Sugeng L, Wienert L, Lang R, Lamberti C Quantification of aortic valve stenosis using transesophageal real-time 3D echocardiographic images. In: Computers in Cardiology, 2009, 2009. IEEE, pp 37-40

18. Barbosa D, Heyde B, Dietenbeck T, Friboulet D, D'hooge J, Bernard O Fast left ventricle tracking in 3D echocardiographic data using anatomical affine optical flow. In: Functional Imaging and Modeling of the Heart (FIMH2013), 2013. pp 191-199

19. Queirós S, Barbosa D, Heyde B, Morais P, Vilaça JL, Friboulet D, Bernard O, D’hooge J (2014) Fast automatic myocardial segmentation in 4D cine CMR datasets. Med Image Anal 18 (7):1115-1131

20. Queirós S, Vilaça JL, Morais P, Fonseca JC, D'hooge J, Barbosa D (2017) Fast left ventricle tracking using localized anatomical affine optical flow. International Journal for Numerical Methods in Biomedical Engineering 33 (11):e2871. doi:10.1002/cnm.2871

21. Queirós S, Morais P, Dubois C, Voigt J-U, Fehske W, Kuhn A, Achenbach T, Fonseca JC, Vilaça JL, D' hooge J (2018) Validation of a novel software tool for automatic aortic annulus sizing in 3D transesophageal echocardiographic images. J Am Soc Echocardiogr 31 (4):515-525.e515

22. Heyde B, Barbosa D, Claus P, Maes F, D'hooge J (2013) Three-dimensional cardiac motion estimation based on non-rigid image registration using a novel transformation model adapted to the heart. In: Statistical Atlases and Computational Models of the Heart. Imaging and Modelling Challenges. Springer, pp 142-150

23. Kasel AM, Cassese S, Bleiziffer S, Amaki M, Hahn RT, Kastrati A, Sengupta PP (2013) Standardized imaging for aortic annular sizing: implications for transcatheter valve selection. JACC Cardiovasc Imaging $6(2): 249-262$

24. Kenny C, Monaghan M (2015) How to assess aortic annular size before transcatheter aortic valve implantation (TAVI): the role of echocardiography compared with other imaging modalities. Heart 101 (9):727-736. doi:10.1136/heartjnl-2013-304689

25. Bland JM, Altman D (1986) Statistical methods for assessing agreement between two methods of clinical measurement. The Lancet 327 (8476):307-310

26. Queirós S, Papachristidis A, Barbosa D, Theodoropoulos KC, Fonseca JC, Monaghan MJ, Vilaça JL, D' hooge J (2016) Aortic valve tract segmentation from 3D-TEE using shape-based B-spline Explicit Active Surfaces. IEEE Trans Med Imaging 35 (9):2015-2025. doi:10.1109/TMI.2016.2544199

27. Prihadi EA, van Rosendael PJ, Vollema EM, Bax JJ, Delgado V, Marsan NA (2018) Feasibility, Accuracy, and Reproducibility of Aortic Annular and Root Sizing for Transcatheter Aortic Valve Replacement Using Novel Automated Three-Dimensional Echocardiographic Software: Comparison with Multi-Detector Row Computed Tomography. J Am Soc Echocardiogr 31 (4):505-514.e503

28. Piazza N, de Jaegere P, Schultz C, Becker AE, Serruys PW, Anderson RH (2008) Anatomy of the aortic valvar complex and its implications for transcatheter implantation of the aortic valve. Circ Cardiovasc Interv 1 (1):74-81 
29. Elattar MA, Vink LW, van Mourik MS, Baan Jr J, Planken RN, Marquering HA (2017) Dynamics of the aortic annulus in 4D CT angiography for transcatheter aortic valve implantation patients. PLoS One 12 (9):e0184133

30. Looi J-L, Lee AP-W, Fang F, Hsiung MC, Sun J-P, Yin W-H, Wei J, Tsai S-K, Wan S, Wong RH (2015) Abnormal mitral-aortic intervalvular coupling in mitral valve diseases: a study using real-time threedimensional transesophageal echocardiography. Clin Res Cardiol 104 (10):831-842

31. Caballero L, Saura D, Oliva-Sandoval MJ, González-Carrillo J, Espinosa MD, García-Navarro M, Valdés M, Lancellotti P, de la Morena G (2017) Three-dimensional morphology of the left ventricular outflow tract: impact on grading aortic stenosis severity. J Am Soc Echocardiogr 30 (1):28-35

32. Khamooshian A, Amador Y, Hai T, Jeganathan J, Saraf M, Mahmood E, Matyal R, Khabbaz KR, Mariani M, Mahmood F (2017) Dynamic Three-Dimensional Geometry of the Aortic Valve Apparatus-A Feasibility Study. J Cardiothorac Vasc Anesth 31 (4):1290-1300

33. Tsang W, Veronesi F, Sugeng L, Weinert L, Takeuchi M, Jeevanandam V, Lang RM (2013) Mitral valve dynamics in severe aortic stenosis before and after aortic valve replacement. J Am Soc Echocardiogr 26 (6):606-614

34. Doddamani S, Bello R, Friedman MA, Banerjee A, Bowers JH, Kim B, Vennalaganti PR, Ostfeld RJ, Gordon GM, Malhotra D (2007) Demonstration of left ventricular outflow tract eccentricity by real time 3D echocardiography: implications for the determination of aortic valve area. Echocardiography 24 (8):860866

35. Flachskampf FA, Wouters PF, Edvardsen T, Evangelista A, Habib G, Hoffman P, Hoffmann R, Lancellotti P, Pepi M, Imaging EAoC (2014) Recommendations for transoesophageal echocardiography: EACVI update 2014. European Heart Journal - Cardiovascular Imaging 15 (4):353-365

36. Papachristidis A, Papitsas M, Roper D, Wang Y, Dworakowski R, Byrne J, Wendler O, MacCarthy P, Monaghan MJ (2017) Three-Dimensional Measurement of Aortic Annulus Dimensions Using Area or Circumference for Transcatheter Aortic Valve Replacement Valve Sizing: Does It Make a Difference? J Am Soc Echocardiogr 30 (9):871-878 


\section{Text Tables}

Table 1 - Patients' baseline characteristics $(n=42)$

\begin{tabular}{|c|c|}
\hline Age (y) & $84.1 \pm 5.2$ \\
\hline Men & $19(45.2 \%)$ \\
\hline NYHA class $\geq$ III & $38(90.5 \%)$ \\
\hline \multicolumn{2}{|l|}{ Surgical risk assessment } \\
\hline Logistic EuroSCORE, \% $(n=9)$ & $10.0 \pm 9.7$ \\
\hline EuroSCORE II, \% $(n=24)$ & $6.2 \pm 6.8$ \\
\hline Porcelain aorta & $0(0.0 \%)$ \\
\hline Frailty & $31(73.8 \%)$ \\
\hline Creatinine $>2 \mathrm{~mm} / \mathrm{dL}$ & $2(4.8 \%)$ \\
\hline \multicolumn{2}{|l|}{ Cardiac risk factors: } \\
\hline Hypertension & $40(95.2 \%)$ \\
\hline Diabetes & $15(35.7 \%)$ \\
\hline Hyperlipidemia & $31(73.8 \%)$ \\
\hline \multicolumn{2}{|l|}{ Medical history } \\
\hline Cardiac surgery & $2(4.8 \%)$ \\
\hline Percutaneous coronary intervention & $22(52.4 \%)$ \\
\hline Preexisting pacemaker/defibrillator & $6(14.3 \%)$ \\
\hline Myocardial infarction & $7(16.7 \%)$ \\
\hline Cardiomyopathy & $4(9.5 \%)$ \\
\hline Stroke & $4(9.5 \%)$ \\
\hline Cerebrovascular disease & $5(11.9 \%)$ \\
\hline Peripheral vascular disease & $4(9.5 \%)$ \\
\hline Chronic obstructive pulmonary disease & $4(9.5 \%)$ \\
\hline Atrial fibrillation & $8(19.0 \%)$ \\
\hline \multicolumn{2}{|l|}{ Clinical parameters } \\
\hline Mean transaortic gradient, $\mathbf{m m H g}(n=41)$ & $51.0 \pm 18.1$ \\
\hline Peak transaortic gradient, $\mathbf{m m H g}(n=41)$ & $73.7 \pm 22 . x 8$ \\
\hline Peak velocity, $\mathbf{m} / \mathbf{s}(n=41)$ & $4.26 \pm 0.67$ \\
\hline Aortic valve area, $\mathbf{c m}^{2}(n=40)$ & $0.71 \pm 0.19$ \\
\hline mPAP, $\mathbf{m m H g}(n=27)$ & $30.9 \pm 10.9$ \\
\hline EF, \% & $57.3 \pm 13.0$ \\
\hline \multicolumn{2}{|l|}{ Calcification severity $(n=41)$ : } \\
\hline - none or mild & $11(26.2 \%)$ \\
\hline - moderate or severe & $30(71.4 \%)$ \\
\hline
\end{tabular}


Table 2 -Maximum/minimum dimensions for the four studied levels, and absolute and relative changes for each

\begin{tabular}{|c|c|c|c|c|c|c|}
\hline & & Maximum & Minimum & Absolute Change & Relative Change & $p$-value* \\
\hline \multirow{2}{*}{ LVOT } & Area & $\begin{array}{c}385.7 \pm 86.3 \\
(228.4-555.8)\end{array}$ & $\begin{array}{c}304.1 \pm 80.5 \\
(143.6-450.0)\end{array}$ & $\begin{array}{c}81.6 \pm 33.4 \\
(33.6-203.2)\end{array}$ & $\begin{array}{c}21.7 \pm 8.2 \\
(8.0-38.7)\end{array}$ & $<0.0001$ \\
\hline & Perimeter & $\begin{array}{c}69.8 \pm 7.9 \\
(53.9-84.3)\end{array}$ & $\begin{array}{c}62.8 \pm 8.3 \\
(44.1-76.6)\end{array}$ & $\begin{array}{c}7.1 \pm 3.0 \\
(2.1-16.5)\end{array}$ & $\begin{array}{c}10.2 \pm 4.2 \\
(2.9-19.6)\end{array}$ & $<0.0001$ \\
\hline \multirow{2}{*}{ AoA } & Area & $\begin{array}{c}421.2 \pm 85.3 \\
(253.8-599.4)\end{array}$ & $\begin{array}{c}362.4 \pm 80.0 \\
(188.2-531.8)\end{array}$ & $\begin{array}{c}58.8 \pm 21.4 \\
(24.1-124.6)\end{array}$ & $\begin{array}{c}14.2 \pm 4.9 \\
(6.1-25.8)\end{array}$ & $<0.0001$ \\
\hline & Perimeter & $\begin{array}{c}72.7 \pm 7.5 \\
(56.5-86.9)\end{array}$ & $\begin{array}{c}67.7 \pm 7.6 \\
(49.5-81.8)\end{array}$ & $\begin{array}{c}5.0 \pm 1.8 \\
(2.1-10.5)\end{array}$ & $\begin{array}{c}7.0 \pm 2.5 \\
(2.7-12.4)\end{array}$ & $<0.0001$ \\
\hline \multirow{2}{*}{ SoV } & Area & $\begin{array}{c}736.8 \pm 190.9 \\
(404.4-1279.4)\end{array}$ & $\begin{array}{c}673.0 \pm 179.1 \\
(378.1-1219.4)\end{array}$ & $\begin{array}{c}63.8 \pm 23.0 \\
(24.4-114.0)\end{array}$ & $\begin{array}{c}8.7 \pm 2.5 \\
(3.9-13.8)\end{array}$ & $<0.0001$ \\
\hline & Perimeter & $\begin{array}{c}96.6 \pm 12.7 \\
(73.0-128.4)\end{array}$ & $\begin{array}{c}92.7 \pm 12.4 \\
(69.9-125.4)\end{array}$ & $\begin{array}{c}3.8 \pm 1.2 \\
(1.6-6.4)\end{array}$ & $\begin{array}{c}4.0 \pm 1.2 \\
(1.8-6.7)\end{array}$ & $<0.0001$ \\
\hline \multirow{2}{*}{ STJ } & Area & $\begin{array}{c}561.1 \pm 152.8 \\
(317.2-964.5)\end{array}$ & $\begin{array}{c}522.7 \pm 145.4 \\
(282.9-924.0)\end{array}$ & $\begin{array}{l}38.4 \pm 15.3 \\
(8.1-68.9)\end{array}$ & $\begin{array}{c}6.9 \pm 2.3 \\
(1.6-10.8)\end{array}$ & $<0.0001$ \\
\hline & Perimeter & $\begin{array}{c}83.2 \pm 11.3 \\
(62.7-109.8)\end{array}$ & $\begin{array}{c}80.3 \pm 11.1 \\
(60.0-107.6)\end{array}$ & $\begin{array}{c}2.9 \pm 0.9 \\
(0.8-4.4)\end{array}$ & $\begin{array}{c}3.5 \pm 1.1 \\
(1.0-5.4)\end{array}$ & $<0.0001$ \\
\hline
\end{tabular}

$\overline{\text { Values are mean } \pm \text { standard deviation (range). Area and perimeter values are presented in } \mathrm{mm}^{2} \text { and } \mathrm{mm} \text {, respectively. }}$

* Two-tailed paired $t$-test between maximum and minimum values.

Table 3 - Intra- and interobserver reproducibility measurements extracted at all levels of interest with the proposed software tool

\begin{tabular}{c|lcccc}
\hline \hline & LVOT & AoA & SoV & STJ \\
\hline Intraobserver & Area & $-0.51^{*} \pm 9.36$ & $0.85^{*} \pm 6.18$ & $1.22^{*} \pm 11.89$ & $0.45^{*} \pm 7.85$ \\
reproducibility & Perimeter & $-0.22^{*} \pm 0.95$ & $0.00 \pm 0.64$ & $0.01 \pm 0.82$ & $0.01 \pm 0.59$ \\
$\begin{array}{c}\text { Interobserver } \\
\text { reproducibility }\end{array}$ & Area & $-1.64^{*} \pm 8.10$ & $0.65^{*} \pm 7.90$ & $-0.39 \pm 9.94$ & $-1.33^{*} \pm 8.51$ \\
\cline { 2 - 6 } & Perimeter & $-0.14^{*} \pm 0.91$ & $0.08^{*} \pm 0.80$ & $-0.07^{*} \pm 0.72$ & $-0.15^{*} \pm 0.69$ \\
\hline
\end{tabular}

Values are mean \pm SD. Area and perimeter values are presented in $\mathrm{mm}^{2}$ and $\mathrm{mm}$, respectively.

*Two-tailed one-sample $t$-test against zero. 


\section{Figure captions}

Fig. 1 Overview of the proposed software tool for dynamic AV measurements extraction. Upon segmenting the AV tract surface (in blue) at a MS frame using the previously presented segmentation and sizing software tool (A), the proposed tracking algorithm is sequentially applied between pair of adjacent frames (forward and backward) to estimate the motion and deformation of the AV tract throughout the full volume sequence (B). From the estimated motion, the short-axis planes passing through the studied levels (in white/red) can be propagated, allowing to extract dynamic measurements across the cardiac cycle (C).

Fig. 2 Tracking results for three representative cases, with associated measurement curves. For each case, the automatically tracked AV tract surface (in blue) at eight frames (distributed over the cardiac cycle) is illustrated, together with the propagated SAx measurement levels (in red/white). The automatically computed dynamic area and perimeter measures for each one of these levels is presented in the right panel.

Fig. 3 Example measurement curves obtained in the three observers' analyses for six cases. For each case, the extracted measurement curves for annular area and perimeter (left and right in each panel, respectively) are illustrated. The measures extracted by the first observer through a segmentation-based analysis at four independent frames are depicted as black triangles, together with the value at the initial MS frame. The shaded region represents the expected LOA (drawn around the average value between Obs1 and Obs2) for area/perimeter measurements taken by different observers when using an interactive analysis with the AV tract segmentation tool (based on the results in Queirós et al. [21]).

Fig. 4 Intra- and interobserver reproducibility for annular (A, B) area and (C, D) perimeter measurements obtained by the proposed tracking software. To obtain a temporal correspondence between frames of all measurement curves, the end-diastolic (ED) and mid-systolic (MS) frames of all sequences were aligned, and the curves' values linearly interpolated over time (independently for each part, i.e. ED to MS and MS to ED). The ends of the whiskers represent the lowest and highest data point still within 1.5 times the interquartile range of the lower and upper quartile, respectively. Outliers were omitted for better visualization. 
Fig. 5 Distribution of the theoretically selected prostheses sizes for distinct time points, as well as the true

3 implanted size. The percentage of sizing agreement for each moment against both mid-systolic and implanted sizes is

4 also depicted. The red dashed lines show the percentage at which the transition between sizes (23 to 26 , and 26 to 29 -

$5 \mathrm{~mm}$ ) occurs for the truly implanted prostheses.

6

.

17

8

9

Fig. 6 Average (A) area, (B), perimeter, and (C) eccentricity index (EI) values measured across the cardiac cycle at the aortic annulus (AoA). Relative change of (D) area, (E) perimeter, and (F) EI values with respect to the end-diastole (last frame; 100\% R-R interval). The vertical bars indicate the standard deviation of the measures across the entire study population. To obtain a temporal correspondence between frames of all measurement curves, the first and last frames of all sequences were aligned, and the curves' values linearly interpolated over time.

13

Fig. 7 Histogram of the temporal phase (as \%R-R) at which the (A) maximum and (B) minimum area, and (C) maximum and (D) minimum perimeter were measured at the aortic annulus (AoA). The red dashed line represents the average mid-systolic phase (as \%R-R) used by the observer to start the analyses (i.e. segmentation stage) across the study population. All measurement curves were temporally aligned as described in Fig. 6

Fig. 8 Average (A, B, C) area, (D, E, F) perimeter, and (G, H, I) eccentricity index (EI) values measured across the cardiac cycle at the left ventricular outflow tract (LVOT), sinuses of Valsalva (SoV) and sinotubular junction (STJ), respectively. Relative change of $(\mathrm{J}, \mathrm{K}, \mathrm{L})$ area, $(\mathrm{M}, \mathrm{N}, \mathrm{O})$ perimeter, and $(\mathrm{P}, \mathrm{Q}, \mathrm{R})$ EI values with respect to the end-diastole (last frame, 100\% R-R interval). The vertical bars indicate the standard deviation of the measures across the study population. To obtain a temporal correspondence between frames, the first and last frames of all sequences were aligned, and the curves' values linearly interpolated over time. 


\section{Appendix A}

To better understand the AoA dynamics (potentially relevant for TAVI prosthesis sizing), Fig. 6 presents the average area/perimeter throughout the cardiac cycle over all subjects, as well as the relative area/perimeter change over time using the value at the end-diastole phase (last frame; ED) as reference. The average (and SD) eccentricity index (EI) was also calculated [34], and its relative change with respect to the ED phase is also depicted. Note that an EI of 0 represents a perfect circle, with higher EI indicating an elliptical geometry. Moreover, Fig. 7 illustrates the distribution of the temporal phase (as a percentage of the cardiac cycle duration) in which the maximum and minimum area and perimeter values were detected for the entire study population. Note that both first and last moments of the cycle correspond to the ED phase, with the average MS time point defined by the observer (used in the segmentation stage and set as the starting point for the tracking) also shown. Note also that, in the study population, the end-systolic (ES) moment occurred at a median $\sim 53 \%$ of the R-R interval.

Overall, both area and perimeter (Fig. 6A, B, D and E) were larger in systole and lower in diastole, which is in agreement with previous reports that used independent delineation-based analyses in multidetector row computed tomography or 3D-TEE images $[9,12,29,30]$. These results demonstrate the adequacy of the proposed software in extracting physiological and clinically-relevant measurements. Moreover, from the computed eccentricity index (Fig. 6C and F), one observed a more circular annular shape during systole, being more oval in diastole, which is also in accordance to the known dynamic conformational changes of the AoA throughout the cardiac cycle $[10,14,29]$.

The fact that the exact phase of maximum and minimum area/perimeter (Fig. 7) varied across the study population also corroborates the relevance of extracting these measures from multiple time points for an accurate prosthesis selection during preoperative TAVI planning, rather than from a single frame. Indeed, the phase of maximum size occurred, in median, at $20 \%$ of the R-R interval (area: $18.8 \% \mathrm{R}-\mathrm{R}, \mathrm{IQR}$ [14.8, 27.0]; perimeter: $19.3 \% \mathrm{R}-\mathrm{R}, \mathrm{IQR}$ [14.8 31.0]), as reported in Blanke et al. [12], which means that early systolic measures are slightly larger than those obtained at the mid-systolic phase, i.e. the indicated measurement phase in current guidelines [35]. In its turn, the phase of minimum size was, in median, at 80\% the R-R interval (area: $81.7 \%$ R-R, IQR [63.0 92.9]; perimeter: 80.0 \%R-R, IQR [65.2, 92.5]), which 
1 is slightly later than the reported in a previous study [12]. This is partly related to a few cases in which the

2 minimum value was found to be the ED frame (the last one in the sequence), which may be associated to

3 some inaccuracy of the tracking algorithm given its distance from the mid-systolic reference frame and thus

4 cumulated error. This result might be improved if one minimizes the number of propagation steps, as

5 reported in Queirós et al. [19]. However, this type of strategies can only be applied to sequences with a

6 complete cycle.

For completeness sake, Fig. 8 presents the measurements' variation across the cardiac cycle for the other three studied levels. Despite the similar trends in relative changes across the cycle for both area and perimeter (larger values in systole and smaller ones in diastole), a distinct magnitude of relative change was obtained over time for each level. Indeed, the LVOT and aortic annulus presented larger relative changes in

11 area and perimeter across the cycle when compared to both SoV and STJ levels (Table 2), with the difference

12 between maximum and minimum measured values being statistically different for all levels. This has been

13 reported for the aortic annulus in several previous studies [9,11-13,32], although the exact amount of change

14 or its significance varied between populations (e.g., with or without aortic stenosis) and between studies (as

15 described in the recent review on the subject in Suchá et al. [10]). Similar findings have also been described

16 for the LVOT $[14,33]$. Of note, when splitting the study population on the basis of the calcification severity

17 (none/mild vs moderate/severe cases; Table 1), no significant differences were observed for the measures'

18 relative changes at any of the studied levels (Appendix B).

Interestingly, the observed relative changes were lower for perimeter, when compared to the area.

20 Such observation has been previously reported for the aortic annulus [12,13], and has led to the suggestion

21 of using perimeter-based values to size the TAVI prosthesis [36]. Note that this lower relative change for

22 perimeter is not only associated to the relative change in AoA size (i.e. mathematically, these two quantities

23 vary in different proportions with respect to the radius), but is particularly associated to the change in the

24 AoA shape itself (see the changes in EI across the cycle in Fig. 6C,F), making the perimeter more robust 25 (i.e. less variable) to differences throughout the cardiac cycle.

With respect to the EI (Fig. 6C, F and Fig. 8G-I and P-R), the AV tract presented a more circular geometry at the SoV and STJ levels, when compared to either AoA or LVOT planes. Moreover, the relative 
1 change of EI was significantly larger at the LVOT level (in a paired t-test against the other levels), which is

2 in agreement with previous studies [14,31]. In contrast, both SoV and STJ had smaller relative changes in

3 EI across the cycle (in paired t-tests against both LVOT and AoA levels). Their larger area/perimeter values

4 in systole can be mostly associated to an increase in size due to higher systolic than diastolic pressures. Note

5 that, between them, the STJ presented a tendency for a lower relative change in area/perimeter values (Table

62 and Fig. 8), which might be explained by the lower elasticity of this anatomical ring [28]. 


\section{Appendix B}

Table 4 presents the average (and standard deviation) of the maximum/minimum area and perimeter measured during the cardiac cycle, and associated absolute and relative differences, for the four studied levels, when splitting the study population on the basis of the calcification severity (none/mild vs. moderate/severe). Note that the calcification score (none, mild, moderate or severe grade) was visually determined by an experienced cardiologist using a preoperative MDCT scan at the time of TAVI planning and was retrospectively gathered for this study. Overall, despite the slightly different maximum/minimum values for some levels (namely LVOT, SoV and STJ), no statistically significant difference was found between groups for the measures' relative changes (in a two-tailed unpaired $t$-test, with Welch's correction). This result suggests that, for our study population, no differences exist in terms of magnitude of

11 conformational changes between patients with lower (none/mild group) or higher (moderate/severe) amount

12 of calcium.

13

14 Table 4 - Maximum/minimum dimensions, and associated absolute and relative changes, for the four studied levels when dividing the study population based on the calcification score into "None/Mild" and "Moderate/Severe" groups

\begin{tabular}{|c|c|c|c|c|c|c|}
\hline & & & Maximum & Minimum & Absolute Change & Relative Change \\
\hline \multirow{4}{*}{ 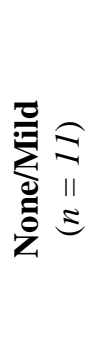 } & LVOT & $\mid \begin{array}{l}\text { Area } \\
\text { Perimeter }\end{array}$ & $\begin{array}{c}396.1 \pm 82.4 \\
70.7 \pm 7.6\end{array}$ & $\begin{array}{c}314.3 \pm 70.4 \\
63.8 \pm 7.6\end{array}$ & $\begin{array}{c}81.8 \pm 30.5 \\
6.9 \pm 2.3\end{array}$ & $\begin{array}{c}20.7 \pm 6.0 \\
9.8 \pm 3.2\end{array}$ \\
\hline & AoA & $\begin{array}{l}\text { Area } \\
\text { Perimeter }\end{array}$ & $\begin{array}{c}421.9 \pm 84.0 \\
728+74\end{array}$ & $\begin{array}{c}363.6 \pm 77.5 \\
67.8+76\end{array}$ & $58.2 \pm 18.3$ & $\begin{array}{c}14.0 \pm 4.0 \\
7.0+20\end{array}$ \\
\hline & SoV & $\mid \begin{array}{l}\text { Area } \\
\text { Derimeter }\end{array}$ & $696.3 \pm 160.7$ & $634.3 \pm 146.0$ & $62.0 \pm 21.2$ & $8.9 \pm 2.1$ \\
\hline & STJ & $\mid \begin{array}{l}\text { Area } \\
\text { Perimeter }\end{array}$ & $\begin{array}{c}538.8 \pm 118.8 \\
82.0 \pm 9.3\end{array}$ & $\begin{array}{c}501.1 \pm 113.9 \\
79.1 \pm 9.0\end{array}$ & $\begin{array}{c}37.8 \pm 11.9 \\
2.9 \pm 0.7\end{array}$ & $\begin{array}{l}7.1 \pm 1.9 \\
3.6 \pm 0.8\end{array}$ \\
\hline \multirow{4}{*}{ 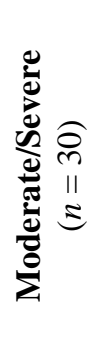 } & LVOT & $\mid \begin{array}{l}\text { Area } \\
\text { Perimeter }\end{array}$ & $\begin{array}{c}382.6 \pm 90.2 \\
69.6 \pm 8.3\end{array}$ & $\begin{array}{c}302.9 \pm 84.9 \\
62.6 \pm 8.6\end{array}$ & $\begin{array}{c}79.7 \pm 33.9 \\
6.9 \pm 3.2\end{array}$ & $\begin{array}{l}21.5 \pm 8.6 \\
10.1 \pm 4.6\end{array}$ \\
\hline & AoA & $\mid \begin{array}{l}\text { Area } \\
\text { Perimeter }\end{array}$ & $\begin{array}{c}421.9 \pm 88.5 \\
72.7 \pm 7.8\end{array}$ & $\begin{array}{c}363.6 \pm 83.0 \\
67.8 \pm 7.8\end{array}$ & $\begin{array}{c}58.2 \pm 22.7 \\
5.0 \pm 2.0\end{array}$ & $\begin{array}{c}14.1 \pm 5.2 \\
6.9 \pm 2.7\end{array}$ \\
\hline & SoV & $\mid \begin{array}{l}\text { Area } \\
\text { Perimeter }\end{array}$ & $\begin{array}{c}755.6 \pm 202.7 \\
97.7 \pm 13.2\end{array}$ & $\begin{array}{c}692.1 \pm 190.7 \\
93.9 \pm 13.0\end{array}$ & $\begin{array}{c}63.9 \pm 24.1 \\
3.8 \pm 1.2\end{array}$ & $\begin{array}{l}8.5 \pm 2.6 \\
4.0 \pm 1.3\end{array}$ \\
\hline & STJ & $\mid \begin{array}{l}\text { Area } \\
\text { Perimeter }\end{array}$ & $\begin{array}{c}573.6 \pm 165.0 \\
84.0 \pm 12.2\end{array}$ & $\begin{array}{c}534.9 \pm 156.5 \\
81.1 \pm 11.9\end{array}$ & $\begin{array}{c}38.7 \pm 16.7 \\
2.9 \pm 1.0\end{array}$ & $\begin{array}{l}6.8 \pm 2.5 \\
3.4 \pm 1.2\end{array}$ \\
\hline
\end{tabular}

Values are mean \pm standard deviation. Area and perimeter values are presented in $\mathrm{mm}^{2}$ and $\mathrm{mm}$, respectively. No statistically significant difference between groups in a two-tailed unpaired $t$-test (with Welch's correction). 
Figure 1

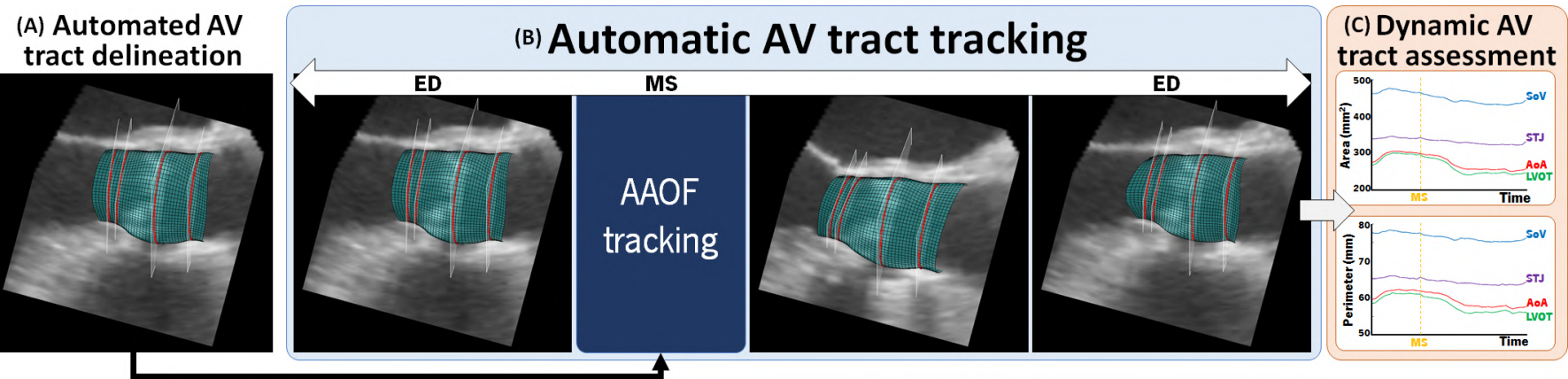

\section{Figure 2}

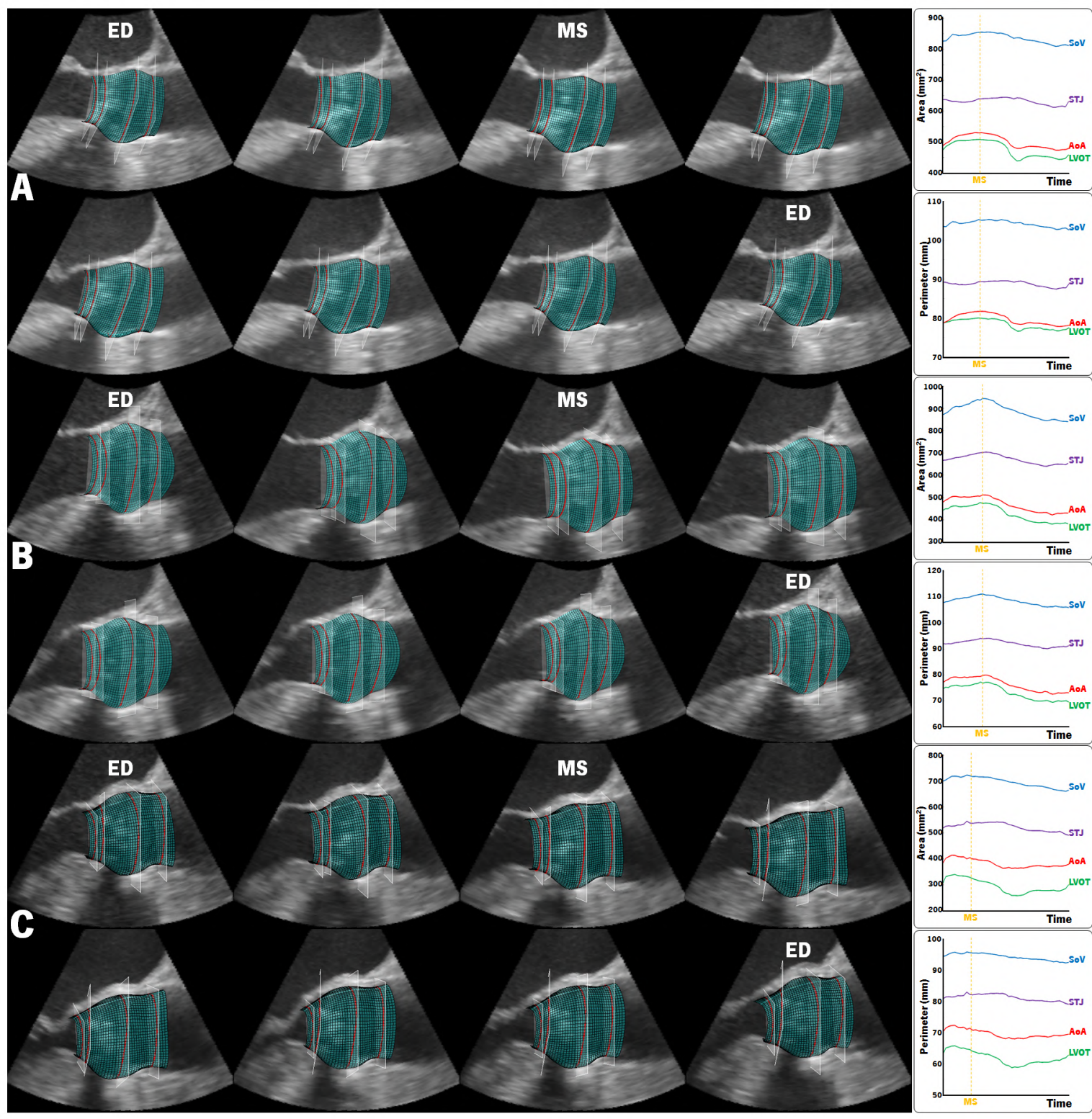




\section{Figure 3}
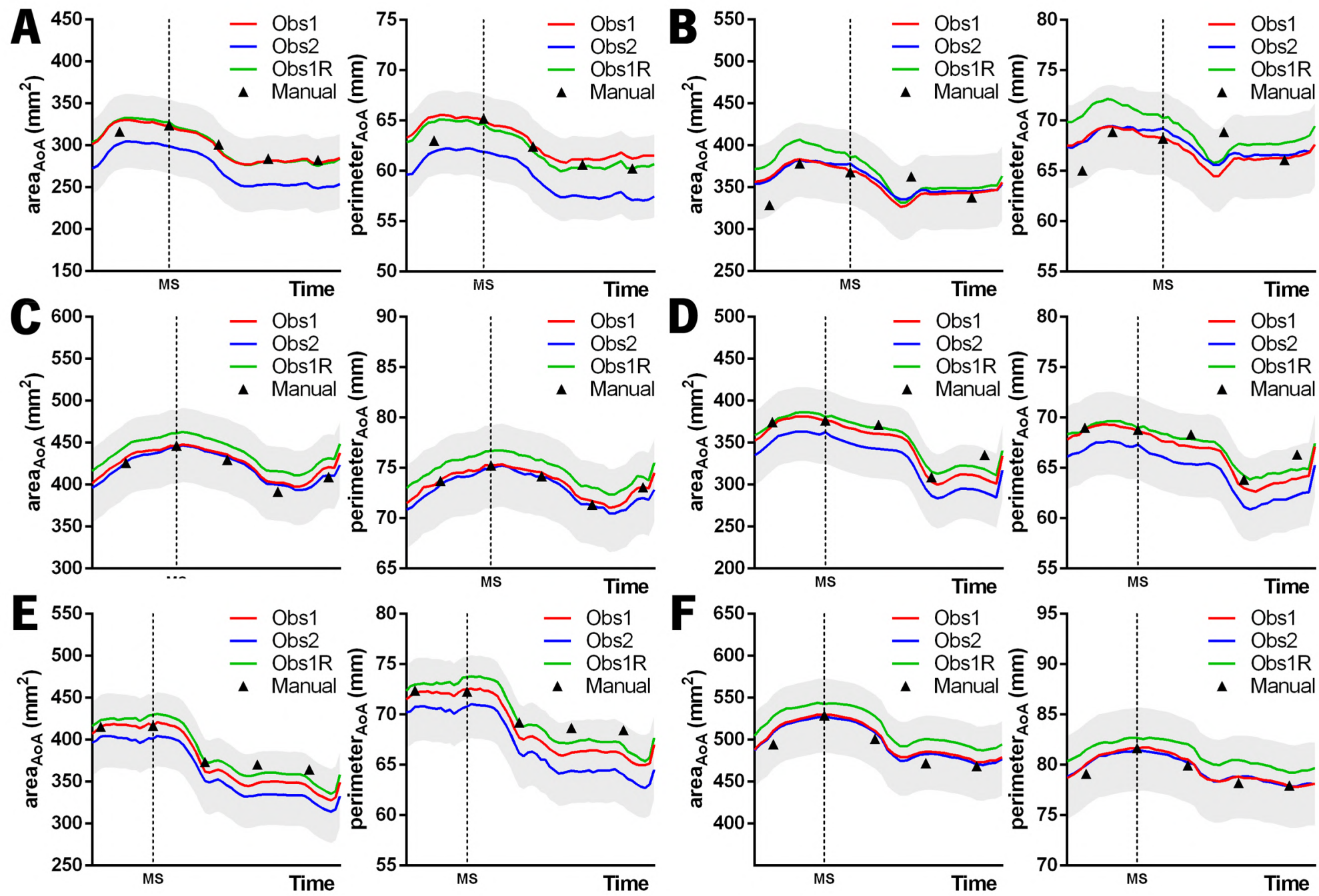

\section{Figure 4}
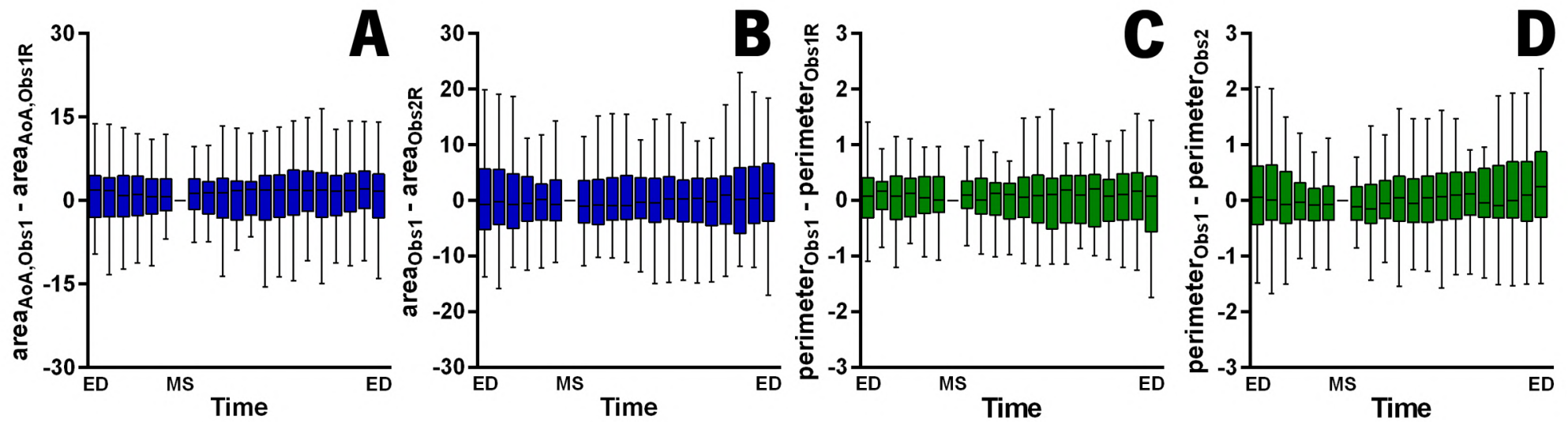


\section{Figure 5}

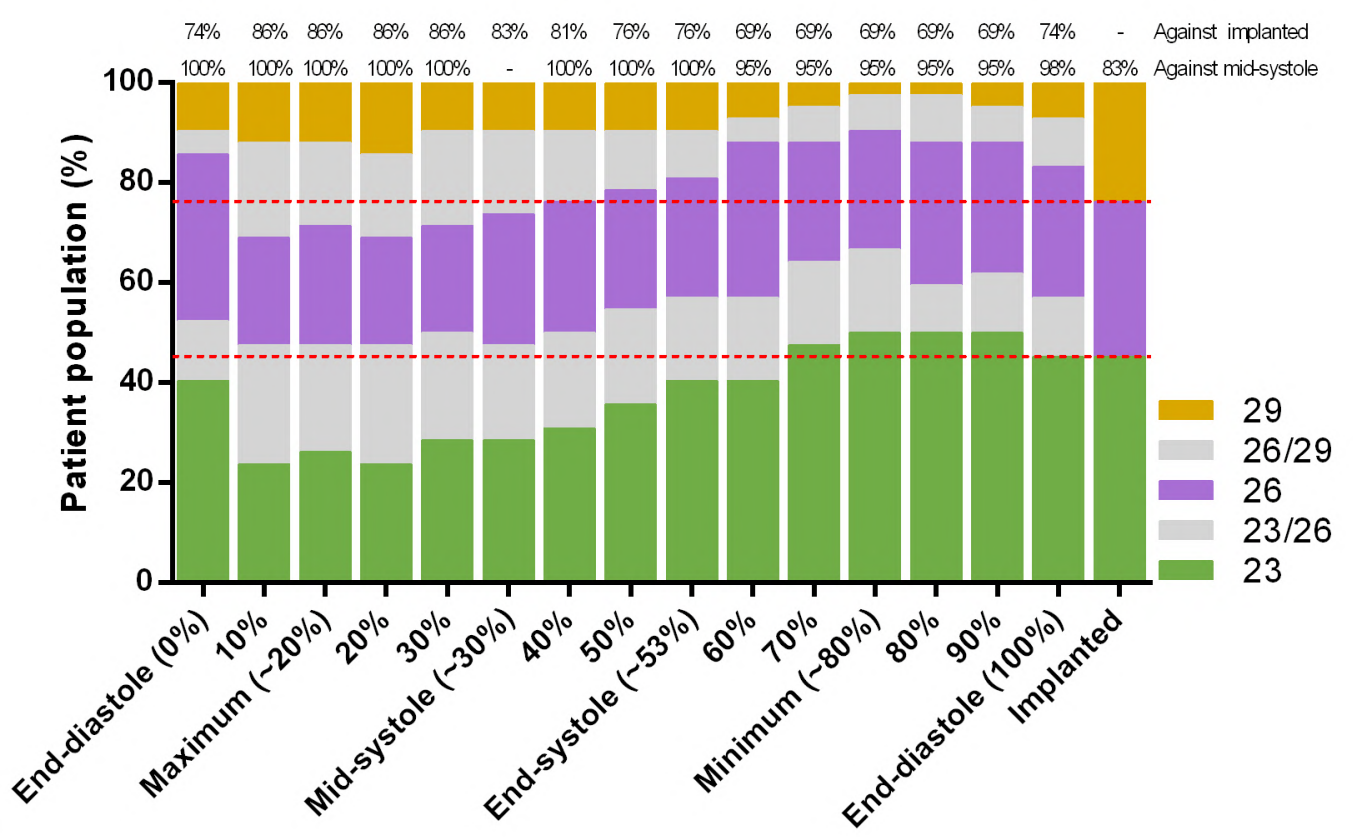

Figure 6
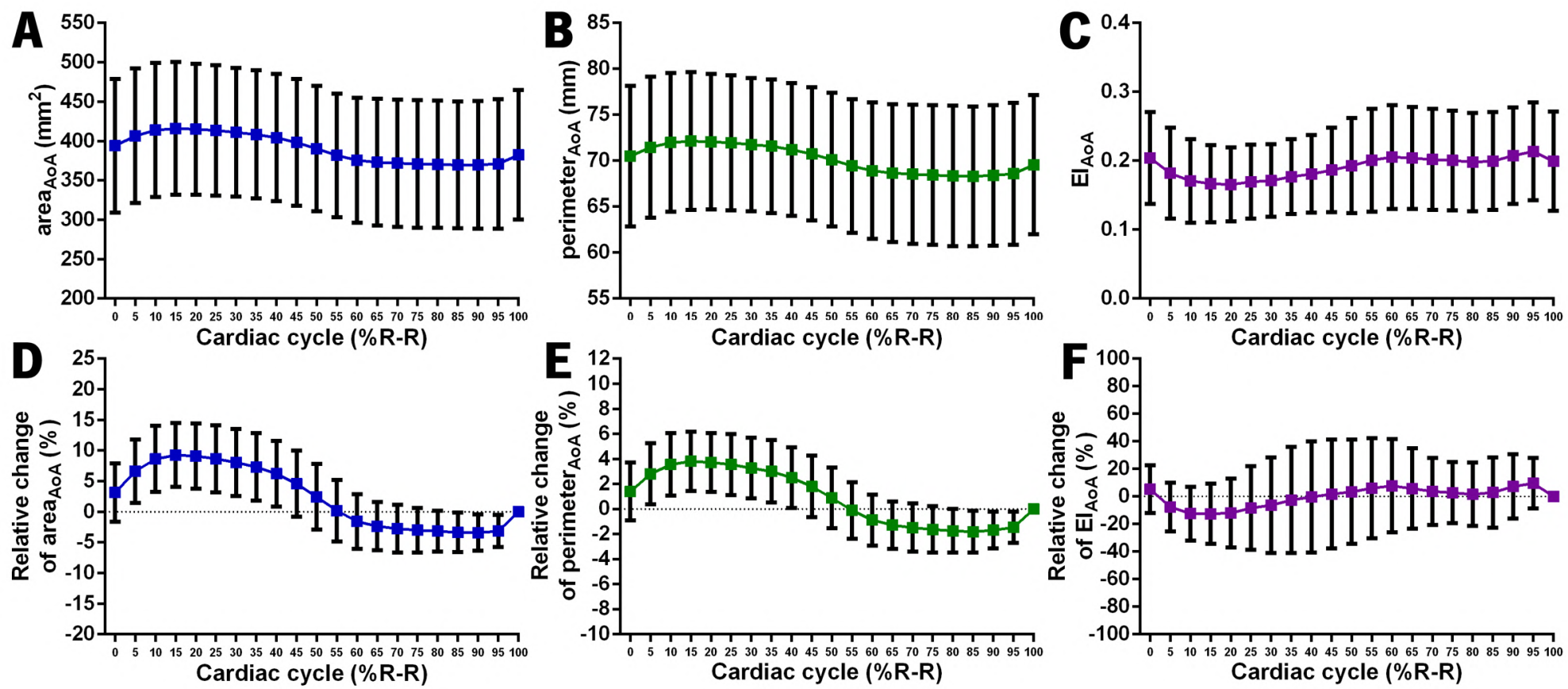

\section{Figure 7}
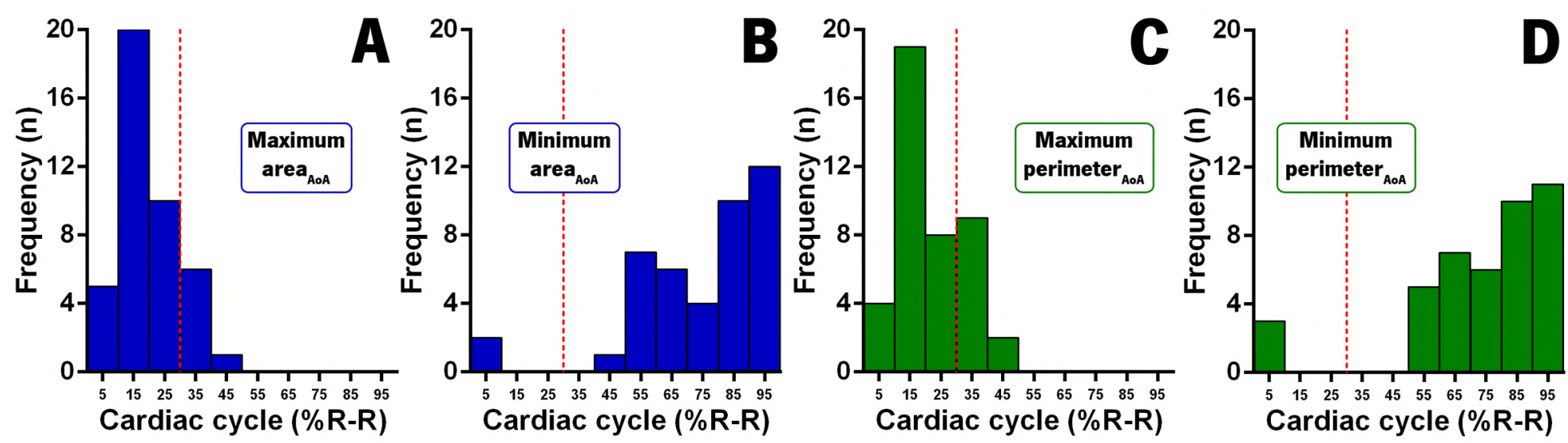
Figure 8
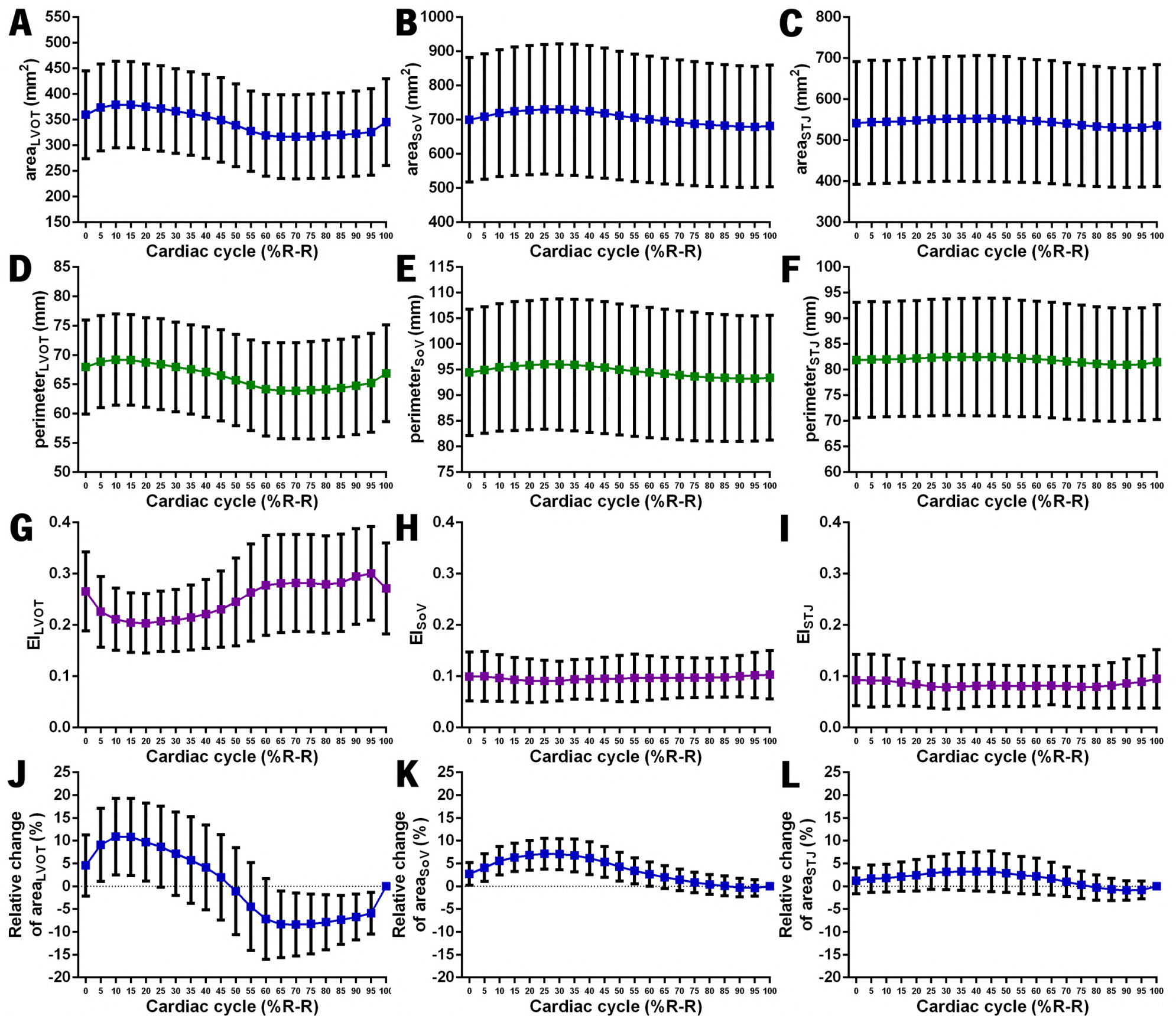

Cardiac cycle (\%R-R)
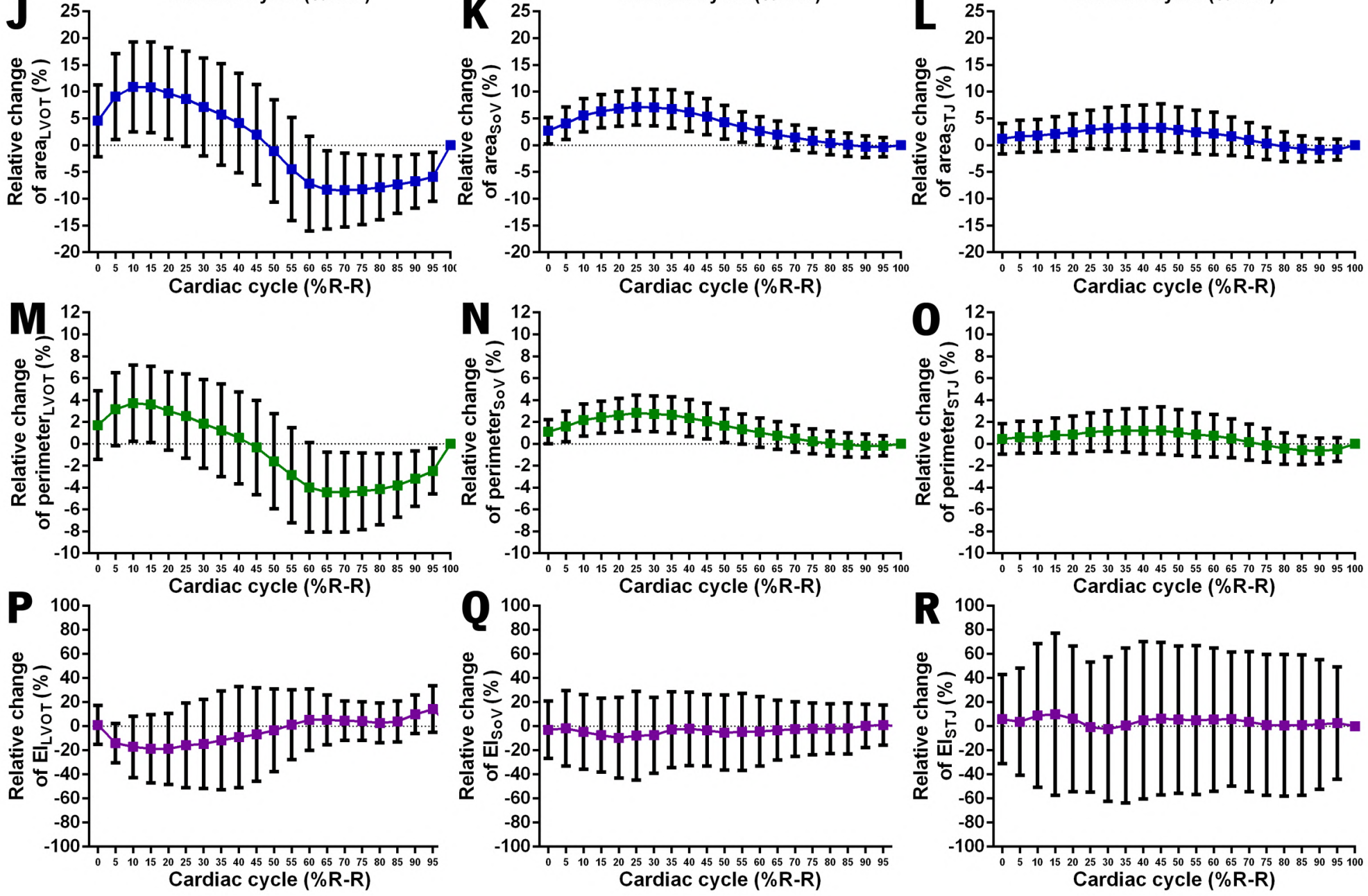